Voix et Images

voixetimages

\title{
Rétrospective Françoise Sullivan
}

\section{Jean-Pierre Duquette}

Volume 7, numéro 3, printemps 1982

Anne Hébert

URI : https://id.erudit.org/iderudit/200354ar

DOI : https://doi.org/10.7202/200354ar

Aller au sommaire du numéro

Éditeur(s)

Les Presses de l'Université du Québec

\section{ISSN}

0318-9201 (imprimé)

1705-933X (numérique)

Découvrir la revue

Citer cet article

Duquette, J.-P. (1982). Rétrospective Françoise Sullivan. Voix et Images, 7(3), 600-602. https://doi.org/10.7202/200354ar d'utilisation que vous pouvez consulter en ligne.

https://apropos.erudit.org/fr/usagers/politique-dutilisation/ 


\title{
Rétrospective Françoise Sullivan
}

\author{
par Jean-Pierre Duquette, Université McGill
}

Discrète, silencieuse. Françoise Sullivan poursuit depuis quarante ans une cuvre multiple dont les axes principaux sont la peinture, la sculpture, la danse et la performance. Liée depuis le tout début à ceux qui formeront le groupe automatiste, elle signera Refus global et son apport particulier au recueil sera le texte d'une conférence de février 1948 intitulée a La danse et l'espoir». S'il reste relativement peu de choses de son œuvre peint des premières années, les sculptures (métal découpé et soudé à partir de 1960. rideaux de scène, plexiglass à la veille de 1970) sont - heureusement plus nombreuses, de mème que les photomontages, et les "tondos» du commencement des années quatre-vingts. Restent également des documents photographiques de chorégraphies et performances échelonnées sur plus de trente ans. C'est l'ensermble de cette production qui était réuni pour la première fois dans une exposition rétrospective au Musée d'art contemporain durant I'hiver 1981-1982. Le mérite de cette manifestation revient au conservateur Claude Gosselin qui a également présidé à l'élaboration d'un superbe catalogue (ce à quoi le M.A.C. ne nous avait guère habitués jusqu'ici) et qui plus est, le catalogue a paru a temps pour l'exposition (autre exploit pour notre musée-du-bout-du-monde).

Les portraits, natures mortes et paysages des années $1940-1945$ sont exécutés dans le sillage du Fauvisme: taches de couleurs fortes et contrastées qui structurent le tableau, formes soulignées d'un trait noir. À l'heure des fusains surréalistes de Fernand Leduc et des gouaches de Borduas pour l'Ermitage (1942), la peinture de Francoise Sullivan demeure encore relativement "traditionnelle". C'est la danse qui lui servira d'abord à sortir décidément des sentiers battus. Après des cours de ballet classique, elle se tourne vite vers l'expérimentation: "ل لai toujours voulu faire de la chorégraphie, composer mes spectacles, créer..." (Catalogue, p. 12). Dès 1945 elle part à New York et l'année suivante elle s'inscrit au studio Boas où l'accent est entièrement sur le mouvement corporel. C'est là qu'elle organise, en janvier 1946, une exposition d'œuvres de ses amis montréalais (Borduas, Fernand Leduc, Mousseau, Riopelle, Pierre Gauvreau et Guy Viau). Automne 1947. elle rentre à Montréal où elle commence à enseigner la danse moderne et présente ses premiers spectacles qui se situent tout à fait dans le courant des idées automatistes (hasard objectif, puisions, rencontres non préméditées, imprévisibles relations...). Dans sa conférence de février 1948, elle souligne 
justement l'importance primordiale des forces mystérieuses du subconscient dans l'acte créateur. Les définitions et précisions contenues dans ce texte important éclairent le sens qu'ont pour Françoise Sullivan le mouvement, le geste: "Avant tout, la danse est un réflexe, une expression spontanée d'émotions vivement ressenties. (...) Il s'agit de remettre en action la surcharge expressive enclose dans le corps humain, cet instrument merveilleux, et de redécouvrir, selon les besoins actuels, les vérités connues déjà d'anciennes peuplades primitives ou orientales (...)*. Elle retrace l'évolution de la danse, d'abord parallèle aux rites religieux, puis, avec le passage au profane, le déclin qui ne laisse qu'une forme vide ne servant plus que de simple divertissement. Seul le mouvement de libération de l'instinct et des forces de l'inconscient redonnera à la danse sa dimension magique, "sacrée". C"est ce que la danse moderne entend réaliser. Françoise Sullivan s'éloigne de la danse en 1956, mais elle y reviendra au début des années soixante-dix.

L'étape suivante dans sa création l'amènera a la sculpture qu'elle pratique surtout de 1960 à 1970 . Elle travaille d'abord le métal découpé et soudé, et/ou plié, puis, à la fin, le plexiglass. La rudesse du matériau s'ordonne au début en assemblages de plaquettes dynamisés à la verticale dans l'espace. Dans une pièce plus importante (« Split Power Grid», 1962), la forme est beaucoup plus stable, plus sereine, l'équilibre s'instaurant entre des plans rectangulaires moins nombreux, moins morcelés, et plus vastes. À partir de 1966, le métal est peint, souvent de couleurs vives (rouge, orange), et l'usage de la couleur coincide avec l'utilisation de disques ou plaquettes circulaires, qui coulent de nulle part en cascades. Entre 1963 et 1966 le matériau prend la texture de métal de rebụt. comme corrodé. les contours percés de trous réguliers. plaques parfois repliées et grossièrement rassemblées. En 1968 et 1969 , elle passe au plexiglass transparent ou vivement coloré qu'elle travaille en spirales ou en ondulations. Elle retiendra encore la spirale pour quelques pièces en bronze dont la matière est comme rongée à l'acide. Puis elle interrompt cette phase créatrice, inquiète devant la perfection mécanique des pièces en plexiglass.

Françoise Sullivan revient a la chorégraphie au début de soixante-dix, en même temps qu'elle s'interroge sur la pertinence de "l'objet" d'art; elle confie bientôt à un critique: "C'est peut-être l'espoir de trouver une nouvelle possibilité qui nous fait délaisser la peinture et la sculpture et qui nous tourne vers autre chose que l'objet. (...) Nous ne sommes plus intéressés aux problèmes de couleur et de forme; nous travailions à un autre niveau. " C'est alors la photographie, le texte et les "actions instantanées» qu'elle pratique pendant une dizaine d'années environ, jusqu'à la veille des années quatrevingts: séquences photo de "promenades», de déambulations (par exemple. du Musée des beaux-arts au Musée d'art contemporain; une autre promenade, "La légende des artistes», devait faire partie du célèbre Corridart en 1976. et retraçait l'histoire culturelle de Montréal, en vitrines et panneaux photographiques). Puis ce sera la suite des a Fenêtres bloquées et débloquées , 
réalisée à Santorin au cours de l'été 1978, et inaugurant une série de photos de portes et de fenêtres bloquées, ouvertures sur l'espace oblitérées, bouchées.

Enfin en 1979, on rentre dans le grand cycle de la circularité: d'abord les photos de Grèce (Tholos et théâtre de Delphes, cercle de pierres à Ferrare, *Accumulations» diverses. Et ce sera, ces deux dernières années, les * tondos*: acryliques sur toile circulaire, et dont chacun offre un a accident " particulier louverture rectangulaire ou carrée, refermée où non, petit tumulus érigé par terre au pied du tondo, corde, papier plastique, bois cassé, tige d'acier, etc.). Le dépouillement extrême de ces formes répétitives, la surface grossièrement recouverte par l'acrylique aux tons sourds ( sales») conferent à ces cuvres une force et une présence étrangement imposantes, comme si l'on se trouvait devant des objets primitifs. A vrai dire, ce thème du cercle s'affirme dans les préoccupations de Françoise Sullivan depuis ses premiers projets de chorégraphie (orbite des planètes), dès les années new-yorkaises; de même dans les mouvements tournoyants qui reviennent dans certaines danses. Les disques et les spirales reparaîtront dans les sculptures. C'est une constante qu'étudie avec beaucoup de pénétration le texte de David Moore « Françoise et l'espoir $x$ ) dans le catalogue.

Sans bruit, sans éclats, Françoise Sullivan élabore depuis les années quarante une cuvre qu'il faut compter ici parmi les plus significatives. Cette rétrospective est venue à point nommé nous le rappeler. 